\title{
A Comparison of Glasgow Coma Score with Computed Tomographic Findings in Cases of Traumatic Brain Injury - A Two Year Experience at a Tertiary care Hospital
}

\author{
Ravi M Godavarthi ${ }^{1}$, Gayatri Manam ${ }^{2}$, Ramakrishna Baru ${ }^{3}$, Sunitha ${ }^{4}$, Naveen Kumar B $^{5}$ \\ ${ }^{1}$ Associate professor, Department of Radiology, ${ }^{2}$ Assistant professor, Department of Radiology, ${ }^{3}$ Professor, Department \\ of Radiology, ${ }^{4}$ Professor Department of Radiology, ${ }^{5}$ Professor Department of Radiology, Narayana Medical College, \\ Chinthareddypalem, Nellore, Andhra Pradesh, India
}

Corresponding author: Dr. Gayatri Manam, Assistant professor, Department of Radiology, Narayana Medical College, Chinthareddypalem, Nellore, Andhra Pradesh, India

DOI: 10.21276/ijcmsr.2018.3.2.27

How to cite this article: Ravi M Godavarthi, Gayatri Manam, Ramakrishna Baru, Sunitha, Naveen Kumar B. A comparison of glasgow coma score with computed tomographic findings in cases of traumatic brain injury $-\mathrm{a}$ two year experience at a tertiary care hospital. International Journal of Contemporary Medicine Surgery and Radiology. 2018;3(2):B111-B115.

\section{A B S T R A C T}

Introduction: Traumatic head injuries are one of the leading causes of disability, morbidity and mortality around the world in all age groups. Our present study aimed at correlation of Glasgow coma score (GCS) with computed tomographic (CT) findings in cases of head injury.

Material and methods: A prospective study for a period of two years was conducted at a tertiary care hospital after ethical committee approval. 330 cases of TBI were subjected to Glasgow coma score scoring and computed tomography of all the cases was performed and findings were noted. Data was analyzed using IBM Corp. releases SPSS statistics for Windows, version 20.0 (NY: IBM Corp)

Results: Of the present study, $64.55 \%$ were males and $34.45 \%$ were females. (M: $F=1.8: 1$ ) and mean age of study group was $30.12 \pm 11.2$ years. $31-40$ years was the commonest age group with TBI. RTA was the most common cause with $42.73 \%$ followed by fall from height (24.85\%). Most of the cases 47.585 were identified as Mild head injury by GCS score and $30.91 \%$ moderate and $21.52 \%$ as severe cases. Loss of consciousness and vomiting were the most common clinical presentations. $89 \%$ of cases had abnormal CT findings with intraxial bleed (72.79\%) as commonest followed by fracture of skull (70.75\%). All the cases of severe head injury had abnormal CT findings.

Discussion: To conclude from our study, patients with low GCS score was considered as severity risk factor in association with more number of abnormal CT findings. Patients with low GCS score are affected by severe morbidity and devastating effects as observed from other studies.

Key words: Glasgow Coma Score, Traumatic Brain Injury, Computed Tomography, Skull Fractures.

\section{INTRODUCTION}

Traumatic brain injury is an alteration in Brain function or anatomic structure due to blunt or penetrating force to the head with associated confusion, altered level of consciousness or focal sensory, motor or other neurologic deficits. Traumatic head injuries are one of the leading causes of disability, morbidity and mortality around the world in all age groups. The incidence of these is variable from one country to another, studies and reports globally state that it is most common in young adults. ${ }^{1}$ Head trauma in young adults and children is one of the main reasons for partial or permanent disability in more than half of the affected individuals making the affected individuals social life miserable. The fatality and disability rates following head trauma vary by severity of the head injury and the time period of diagnosis of the severity and management options with proper care.
Following a head injury the unfavourable outcomes like death, disability can be higher than $20 \% .^{2}$ Epidemiological studies state that globally 5 million admissions occur because of head injury and with considerable mortality in developing countries. The severity of the head injuries and management is clinically based on Glasgow coma scale (GCS) which was developed to describe the level of consciousness in patients with head injuries. The GCS tool has been widely used since 1974 after the development by Teasdale and Jennet, as triage tool and also as a prognostic indicator in cases with TBI. The advantage of GCS is it comprises a set of very simple and easy to perform physical examinations. Based on GCS scoring system, head injuries are categorised as Mild (with score 13-15), moderate (8-13) and severe (3-8). The ability to predict patient outcome after TBI has an important role in clinical practice and research. ${ }^{3}$

Besides clinical evaluation by GCS scoring, intracranial 
lesions in these patients can be detected early by Computed tomography (CT) which remains the primary investigation of choice in most of the cases of TBI in places where the services are available. Early detection of the lesions in TBI by using CT imaging can improve the context of clinical management with a better outcome in these patients. Despite high advantages of CT imaging this procedure may not be available in all the settings and is also associated with certain contraindications. In recent years CT scanning has become a routine investigation and been ordered in all the cases of head injury from the emergency department. Most of the literature reports that CT scans are necessary immediately after head injury and also during follow up also after treatment interventions. Hence developing possible alternative modalities to avoid unnecessary CT scans and hazards of radiation is necessary in cases of TBI. ${ }^{4}$

Our present study aimed at correlation of GCS score with computed tomographic findings in cases of head injury and to evaluate that GCS scoring can be used as an alternate tool in clinical management of head injuries in settings where CT scans are not available or contraindicated.

\section{MATERIAL AND METHODS}

\section{Setting of the study}

The present prospective study was conducted at a tertiary care hospital for a period of two years from January 2015 to December 2017. The tertiary care centre is a 1050 bedded hospital with emergency trauma care unit and catering the needs of around 3-5 lakh population in southern India. The study was approved by the institutional ethical committee and all the study guidelines of the committee were followed. A written informed consent was obtained from all the cases in the study or from the accompanying person of cases if not possible from the cases included in the study.

\section{Participants of the study}

All the patients with history of traumatic head injury by any means referred from the emergency and fulfilling the inclusion criteria of the study were taken as study cases. The Glasgow coma scale of all the cases was noted on arrival at the emergency by emergency physician for all the cases. In case of wound examination, the type of wound, depth, size shape of the wound was noted. Thorough physical and clinical examination of the cases including presence of bleeding, swelling in any part of the scalp, orientation of the case, responsiveness all were noted. The patient's demographic features such as age, sex, clinical data such as type of injury, time duration, risk factors like nausea, vomiting, syncope etc were noted and unrelated risk factors like coagulopathy, drugs or alcohol use, epilepsy, previous neurological surgery all were noted in a separate predesigned structured questionnaire sheet. Patient's neurological assessment was done by a neurologist and all the answers for the questions were collected from the patient itself or if not possible from the accompanying person or companion or by witness report.

\section{Inclusion criteria}

Patients $>18$ years of age

History of traumatic brain injury not less than 12 hours to exclude any delayed effects of development after injury.

\section{Exclusion criteria}

History of coagulation disorders, seizures, previous history of neurosurgery.

Known hypertensives

Patients with known history of Cerebro vascular accidents

After initial thorough clinical assessment, patients severity of the head injury was graded as mild head injury if Glasgow coma score (GCS) was 13-15, moderate head injury if GCS was $9-12$ and severe if GCS was $3-8 .^{5}$

\section{CT scanning Procedure}

All the patients included in the study irrespective of GCS score were subjected to Cranial CT scans without intravenous administration of contrast agent. CT scans were performed with patients in dorsal decubitus position, with single slice helical Somaton balance CT equipment (Siemens Medical solutions, Germany) utilising $130 \mathrm{kVp}$ and $80 \mathrm{mAs}$. Axial sections were performed, parallel to the infraorbital line, with $5 \mathrm{~mm}$-thcik slices in the region of posterior fossa and $10 \mathrm{~mm}$ at other areas of the skull.

All the images were analyzed both on soft tissue windows (200W and 40C for skull base and 80W and $35 \mathrm{C}$ for the Brain) and the bone structures (1500W and 450C) by a senior radiologist and the findings were noted.

\section{STATISTICAL ANALYSIS}

For continuous variables, mean \pm standard deviation was used and frequency (Percentage) was used for categorical variables. Data was analyzed using IBM Corp. releases SPSS statistics for Windows, version 20.0 (NY: IBM Corp)

\section{RESULTS}

The present study was conducted for a period of two years in Department of radiology with association from Department of Emergency medicine and included 330 patients with history of traumatic head injury. The cases were referred from the Emergency unit after clinical and neurological systemic examination and calculating the GCS score. The score was blinded for the radiologist examining the case for avoiding bias in reporting.

Figure -1 summarizes the sex wise distribution of cases in the study, majority were males with 213 cases $(64.55 \%)$ and females with 117 cases (34.45\%). (Sex ratio $M: F=1.8: 1$ ) The age range of the study group was 11-78 years in the study with mean age of $30.12 \pm 11.2$ years. The mean age \pm standard deviation of the age of the males was $31.2 \pm 12.1$ years and females were $34.1 \pm 10.1$ years in the study. The highest numbers of head injuries were noted in the interval of 31-40 years with $32.12 \%$ followed by $41-50$ years $(24.85 \%)$ and $19-$ 30 years (16.97\%). [Figure-2]

The main cause of Traumatic brain injury (TBI) was road traffic accident $(141 / 330,42.73 \%)$ with males $(55.40 \%)$ and females $(19.66 \%)$ followed by fall from a height (82/330, $24.85 \%$ ) with females (41.03\%) and males (15.96\%), physical assault (75/330, 22.73\%) almost equally distributed among males and females (22-24\%). The cause was unknown among 32 cases (9.7\%). Based on the Glasgow Coma scale assessed by emergency physician at emergency, cases of the study were categorized with mild head injury (GCS-13-15), Moderate 


\begin{tabular}{|c|c|c|c|}
\hline Parameter of the study & $\begin{array}{c}\text { Male } \\
\text { (No) (\%) }\end{array}$ & $\begin{array}{l}\text { Female } \\
\text { (No) (\%) }\end{array}$ & $\begin{array}{c}\text { Total } \\
\text { (No) (\%) }\end{array}$ \\
\hline \multicolumn{4}{|l|}{ Cause of Injury } \\
\hline RTA & $118(55.40)$ & $23(19.66)$ & $141(42.73)$ \\
\hline Assault & $47(22.07)$ & $28(23.93)$ & $75(22.73)$ \\
\hline Fall & $34(15.96)$ & $48(41.03)$ & $82(24.85)$ \\
\hline Unknown & $14(6.57)$ & $18(15.38)$ & $32(9.70)$ \\
\hline \multicolumn{4}{|l|}{ Type of Injury } \\
\hline Mild (GCS:13-15) & $98(46.01)$ & $59(50.43)$ & $157(47.58)$ \\
\hline Moderate (GCS: 8-13) & $68(31.92)$ & $34(29.06)$ & $102(30.91)$ \\
\hline Severe (GCS: 3-8) & $47(22.07)$ & $24(20.51)$ & $71(21.52)$ \\
\hline \multicolumn{4}{|c|}{ Clinical Presentations of cases } \\
\hline LOC & 178 & 88 & $266(80.61)$ \\
\hline vomiting & 148 & 70 & $218(66.06)$ \\
\hline seizure & 71 & 21 & $92(27.88)$ \\
\hline Black eyes & 30 & 11 & $41(12.42)$ \\
\hline headache & 41 & 53 & $94(28.48)$ \\
\hline ENT bleeding & 20 & 18 & $38(11.52)$ \\
\hline CSF Rhinorrhoea & 10 & 11 & $21(6.36)$ \\
\hline
\end{tabular}

\begin{tabular}{|l|c|}
\hline CT Findings & Frequency (\%) \\
\hline Skull Fractures & $208(70.75)$ \\
\hline Extra axial bleed & $124(42.17)$ \\
\hline Isolated Subdural & 78 \\
\hline Isolated subarachnoid & 28 \\
\hline Isolated Epidural & 8 \\
\hline Combined & 10 \\
\hline Intra axial Bleed & $214(72.79)$ \\
\hline Frontal lobe & 148 \\
\hline Parietal Lobe & 178 \\
\hline Occipital & 78 \\
\hline Temporal Lobe & 102 \\
\hline Mid-Brain & 14 \\
\hline Combined & 184 \\
\hline Intra ventricular Bleed & $28(9.5)$ \\
\hline Brain stem Bleed & $4(1.4)$ \\
\hline Cerebellar Bleed & $4(1.4)$ \\
\hline Intracavitory Bleed & $108(36.73)$ \\
\hline Cerebral edema & $148(50.34)$ \\
\hline Table-2: Abnormal CT findings among the cases in the study \\
\hline
\end{tabular}

\begin{tabular}{|l|c|}
\hline Skull Fracture & Frequency (\%) \\
\hline Blow out Fracture & $5(2.4)$ \\
\hline Facial Bone fracture & $13(6.25)$ \\
\hline Temporal bone fracture & $33(15.87)$ \\
\hline Occipital Bone Fracture & $55(26.44)$ \\
\hline Parietal Bone Fracture & $78(37.50)$ \\
\hline Frontal bone Fracture & $18(8.65)$ \\
\hline Base of skull fracture & $6(2.88)$ \\
\hline \multicolumn{2}{|c|}{ Table-3: Types of skull fractures recorded in the study } \\
\hline
\end{tabular}

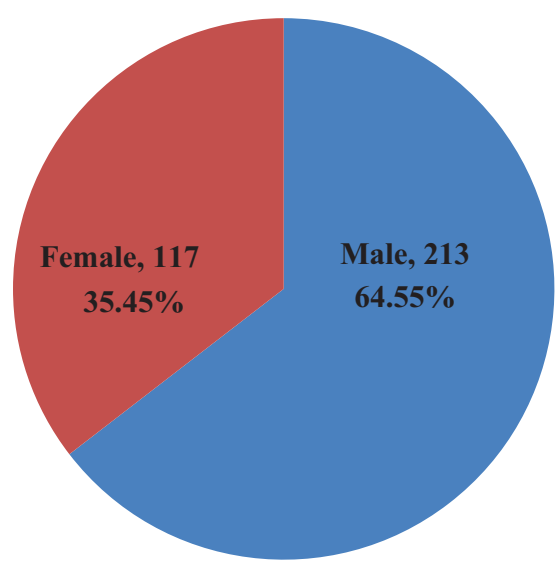

Figure-1: Sex wise distribution of cases in the study

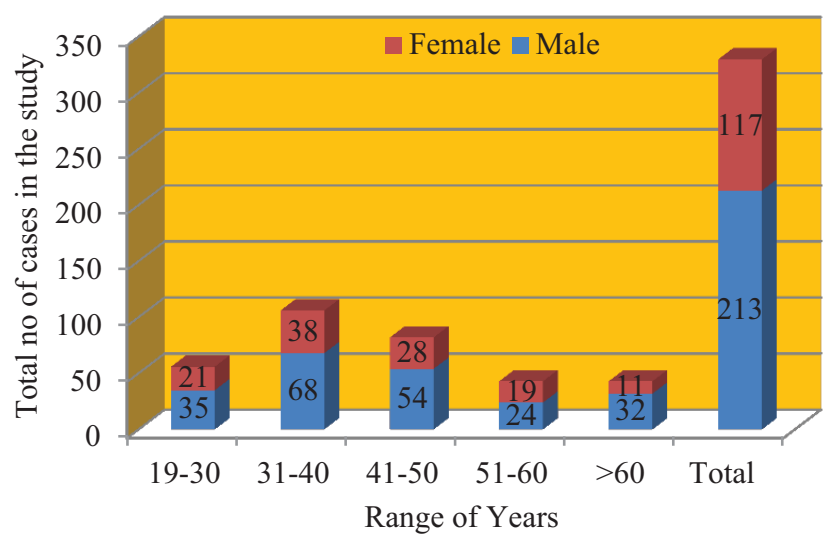

Figure-2: Gender and Age wise distribution of Cases in the study

(21.52\%) with male (22.07\%) and females (20.51\%). Loss of consciousness and vomiting were the most common clinical presentations in patients of our study. Other less common features are summarized in Table-1. [Table-1]

Figure- 3 explains the type of severity of the cases with the cause of head injury. RTA was the main etiological factor and females (29.06\%) and severe head injury cases were 71 head injury (GCS-8-13) and severe head injury (GCS-3-8). In the present study, 157 cases (47.58\%) were categorized as mild, with males $(46.01 \%)$ and females $(50.43 \%)$, moderate mild, with injury with 102 cases $(30.91 \%)$ with males $(31.92 \%)$ 
— Severe (GCS: 3-8,-, Moderate (GCS: 8-13)— Mild (GCS:13-15)

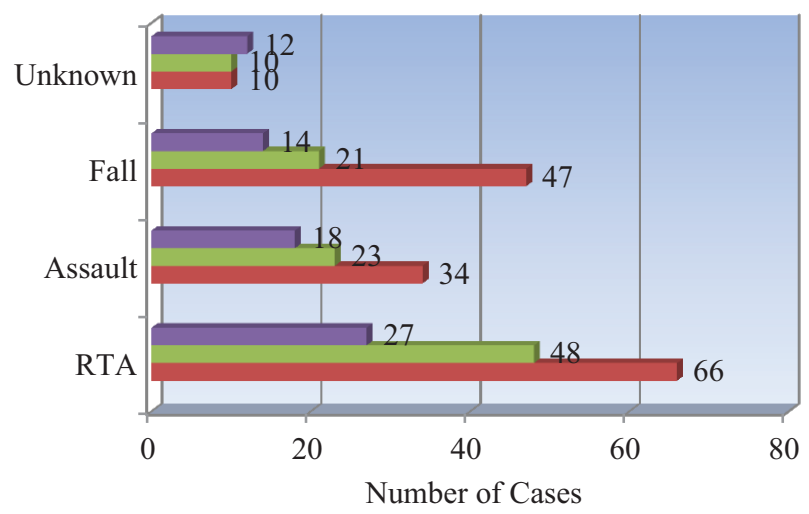

Figure-3: Cause of Injury and Type of head injury

in all cases with mild, moderate and severe head injury. In 71 cases of severe head injury, RTA accounts for 38.03\%, followed by assault (25.35\%), fall (19.72\%) and unknown cause in $16.9 \%$.

Figure -4 explains that of all 330 cases of TBI, 36 cases had normal findings on CT (11\%) and abnormal CT findings in 294 (89\%) of cases. Of the 36 cases of normal CT, 34 were categorized as mild injury and 2 cases with moderate injury at time of diagnosis. Table- 2 summarize the various abnormal CT findings in the study cases. The major alterations recorded in the CT was intra axial bleed (72.79\%) followed by skull fractures (70.75\%), Cerebral edema (50.34\%), Extra axial bleed (42.17\%) Intracavitory bleed (36.73\%) and other less common findings were cerebellar bleed, ventricular bleed and brainstem bleed. However a combination of two or more was observed in 147 cases.

In cases of extra axial bleed, isolated subdural haemorrhage was the commonest (78 cases) followed by isolated subarachnoid haemorrhage (28 cases) and combined in 10 cases. The least was isolated Epidural in 8 cases of study. In cases with Intra axial bleed, combined cases of haemorrhage was observed in 184 cases followed by parietal (178 cases), frontal (148 cases) and temporal areas (108 cases). Mid brain was the least affected area with only 14 cases in the study. Of the 208 cases of skull fracture, parietal bone fracture was the commonest with $37.50 \%$ followed by occipital (26.44\%), Temporal (15.87\%) and other less common were Frontal bone (8.65\%), Facial (6.25\%), Base of skull (2.8\%) and Blowout fracture (2.4\%). [Table-3]

Other less common incidental findings observed but not related to trauma were atrophy of brain, lacunae, calcifications, arachnoid cysts and sinus disease.

\section{DISCUSSION}

Traumatic brain injury is one of the major public problem which has gained wide importance. Literature and reports of various studies state that these injuries account for $3 \%$ to $10 \%$ of deaths and these deaths occur mostly in young adults which is of real concern. In India the figures of mortality, morbidity and disability in cases of TBI due to road traffic agents are a real threat to the country. Higher incidence is observed mostly in young adults.

In the present study, a total of 330 cases were studied and male accounting for majority with $65 \%$ which is similar to most of the reports globally. Men are more exposed to outer work and violence activities than females which are risk factors for TBI. In general men are more accessible to automobiles like two wheelers and are being exposed more to a threat of accidents than females. Majority of the cases in our study were found in $2^{\text {nd }}$ and $3^{\text {rd }}$ decade of life which is most vulnerable group with active participation in outer works during regular daily life. Findings of our study with regard to gender distribution and age group were on par with findings of Bhandari et al who reported the incidence of men as $82 \%$ their study. ${ }^{6}$ In the present study, the incidence of RTA was lesser in $>50$ years age group as reported by other studies. Fall from the height was second most common cause in our study, more common in females than males than RTI. Fall from height were more prevalent in elderly population however such data is variable from population to population and region to region. Findings of our study correlate with the findings of Ashikaga $\mathrm{R}$ et al who reported that fall from a height is common cause of TBI among females. ${ }^{7}$

Of the 330 cases in the study, majority were graded as Mild TBI with GCS (13-15) (47.58\%) with next followed by moderate (30.91\%). Findings of our study were on par with the findings of Akanji etal who reported the incidence of Mild TBI in his study as $54.2 \% .^{8}$ In our study, incidence of Mild TBI was higher in females than males which was a typical finding observed which is contrary to the findings of Bahloul $\mathrm{M}$ et al who stated that all types of TBI were higher in males than females. ${ }^{9}$ Loss of consciousness and vomiting were the common clinical presentations in our study on par with many other studies reported. Bleeding from the nose and CSF Rhinorrhoea was found in cases with severe TBI. Prasad et al in their study reported nausea and vomiting, headache and Loss of consciousness as the prime clinical presentations which correlate with our study. ${ }^{10}$

Table-2 highlights that intraxial bleed and fractures of the skull were the most common abnormal findings in the computed tomography of cases in the study. Differences in the CT findings vary according to the severity of the trauma and the GCS scoring of the case. In our study, in cases with mild TBI subgaleal haematomas and skull fractures accounted for $54 \%$ and $25 \%$ which is similar to the findings of Asaleye C.M et al who reported the incidence of hematomas as $58 \%$ and fractures as $28 \%$ in his study. ${ }^{11}$ Some authors have reported brain contusion, palpebral haematomas as common findings of TBI in CT which is contrary to the findings of our study. However few studies also reported subdural, sub arachnoid and extradural hematomas as common findings in cases of mild TBI. ${ }^{22}$

In cases of moderate TBI, intraxial bleed mostly in the frontal, temporal and parietal lobe were found in $54 \%$ of cases and associated skull fractures seen in $27 \%$ of the cases of moderate TBI. Similar findings were reported by Farshchian et al in his study with $32 \%$ of skull fractures and $52 \%$ of intraxial bleeds in his study. ${ }^{13}$ However contrary to the findings of our study few studies reported higher incidence of subarachnoid and subdural haemorrhages as most common findings in cases of moderate TBI. In cases of severe TBI, $100 \%$ of cases had abnormal CT 
findings. The commonest finding being skull fractures, with subarachnoid, subdural and epidural haemorrhages accounting for nearly equal to incidence of skull fractures. Majority of the studies reported that abnormal CT findings, with worst prognosis are associated with severe TBI. In our study, intraventricular bleed and Brain stem bleed was associated with Sever TBI and had worst prognosis and patients were ventilated.

\section{CONCLUSION}

To conclude from our study, patients with low GCS score was considered as severity risk factor in association with more number of abnormal CT findings. Patients with low GCS score are affected by severe morbidity and devastating effects as observed from other studies. ${ }^{14}$

\section{REFERENCES}

1. World Health Organization (WHO). Neurological Disorders: Public Health Challenges; WHO: Geneva, Switzerland, 2007; p. 164.

2. Stein SC, Ross SE. Mild head injury: a plea for routine early CT scanning. J Trauma 1992; 33(2): 11-13.

3. Teasdale G,Jennett B.Assessment of coma and impaired consciousness: a practical scale. Lancet 1974; 2 (4):81-4.

4. Schackford SR, Wald SL, Ross SE, et al. The clinical utility of computed tomographic scanning and neurologic examination in the management of patients with minor head injuries. J Trauma 1992; 33 (6):385394.

5. Traumatic Brain Injury in the United States. Available online: http://www.cdc.gov/ traumaticbraininjury/pdf/ blue_book.pdf (accessed on 3 December 2013).

6. Bhandari R, Mahato IP, Poudel M, Giri R. Head injury: a case profile study from Eastern region of Nepal. Health Renaissance 2010; 8(2): 110-3.

7. Ashikaga, R., Araki, Y., Ishida, O. MRI of head injury using FLAIR. Neuroradiology 1997;39(1):239-242.

8. Akanji AO, Akinola RA, Balogun BO, Akano AO, Atalabi OM, Akinkunmi MA, et al. Computed tomography scan and head injury: The experience in a tertiary hospital in Nigeria. A cross sectional study.[Last accessed on 2016 Aug 15]; Acad J. 2015;6(3):1-15.

9. Bahloul M, Chelly H, Gargouri R, Dammak H, Kallel H, Ben Hamida C, et al. Traumatic head injury in children in South Tunisia epidemiology, clinical manifestations and evolution 454 cases. Tunis Med.2009;87(4):28-37.

10. Prasad K. The Glasgow Coma Scale: a critical appraisal of its clinimetric properties. J Clin Epidemiol. 1996 Jul; 49(7):755-763.

11. Asaleye C.M., famurewa O.C, komolafe E.O. et al. The pattern of computerized Topographic findings in moderate and severe head, injuries in ILE- IFE, Nigeria West African Journal of Radiology. April 2005 Vol 12 number.

12. Stein SC, Ross SE. Mild head injury: a plea for routine early CT scanning. J Trauma. 1992; 33(5):11-3.

13. Farshchian, N., Farshchian, F., and Rezaei, M. Correlation between Glasgow coma scale and brain CT-scan findings in traumatic patients. Journal Of Injury And Violence Research 2012;4(3).

14. Gennarelli TA, Spielman GM, Langfitt TW, et al.
Influence of the type of intracranial lesion on outcome from severe head injury.J Neurosurg. 1982; 56(3):26-32.

\section{Source of Support: Nil; Conflict of Interest: None}

Submitted: 05-05-2018; Accepted: 04-06-2018; Published online: 15-06-2018 